\title{
O Papel da Auditoria no Sistema Único de Saúde
}

THE AUDIT ROLE IN THE BRAZILIAN PUBLIC HEALTH SYSTEM

César Augusto Trinta Weber ${ }^{(*)}$

Ronaldo Bordin ${ }^{(\star \star)}$

\section{RESUMO}

O artigo debate o papel da auditoria no sistema público de saúde no Brasil, observando-se os modelos de Estado configurados pela Constituição Federal de 1967, em especial a criação do Instituto Nacional de Assistência Médica da Previdência Social e o modelo desenhado pela Constituição Federal de 1988, com a instituição do Sistema Único de Saúde (SUS). Estabelece as relaçōes, nuança e diferenças com outras instâncias de controle, tanto interno quanto externo, tais como o Tribunal de Contas do Estado e os Conselhos de Saúde, se presentes nestes períodos históricos. Consiste em um estudo de caso com os cinco municípios que sofreram auditoria de gestão nos seus sistemas municipais de saúde, por iniciativa do gestor estadual, no Estado do Rio Grande do Sul, em 2003. Como instrumento de coleta de dados foi empregado pesquisa documental e um questionário com questōes abertas. Dos cinco municípios, somente um cumpriu as exigências e prerrogativas normativas para o nível de habilitação a gestão em que se encontrava.

\section{Palavras-chave}

Auditoria; Auditoria Médica; Saúde Pública; Gestão de Saúde; Financiamento.

(") Médico Auditor da Secretaria de Estado da Saúde do Rio Grande do Sul (SES/RS). Especialista em Administraçāo Hospitalar/PUCRS, Especialista em Gestāo de Saúde/UFRGS, Mestrando em Educação/ULBRA-RS. E-mail:<trintaweber@hotmail.com>.

$\left({ }^{\star *}\right)$ Professor Adjunto do Departamento de Medicina Social, Faculdade de Medicina, Universidade Federal do Rio Grande do Sul (UFRGS). Membro do Conselho Estadual de Saúde do Rio Grande do Sul (CES/ RS). E-mail:<bordin@logic.com.br>. 


\section{ABSTRACT}

The article discusses the role of auditing in the Brazilian public health system, according to Federal Constitution of 1967, in which the Instituto Nacional de Assistência e Previdência Social was created and to Federal Constitution of 1988, in which the Brazilian Public Health System (Sistema Único de Saúde) was created. This article describes the relationships and differences in internal and external control by the State Audit General (Tribunal de Contas do Estado) and the Health Councils. Five cities subjected to management audit by authority of the State of Rio Grande Sul in 2003 were studied. Information was collected by document research and interviews. Only one of these five cities met the audit requirements for its level of management.

\section{Key words}

Audit; Management Audit; Public Health; Health Management; Financing.

\section{INTRODUÇĀO}

À auditoria do SUS compete controlar o sistema público de saúde, ou seja, o fiel e regular cumprimento dos preceitos constitucionais, através da proba aplicação dos recursos públicos destinados a este fim, na forma da lei e no interesse público. Isto significa dizer, a auditoria é uma atividade de caráter técnico normativo que exerce o controle das políticas públicas planejadas e executadas pelos gestores e conselhos de saúde, bem como dos impactos na qualidade de saúde da população. Nesse sentido, a Auditoria observa a eficiência, eficácia e efetividade das açōes e serviços postos em movimento pelos gestores de saúde.

A Constituição Federal de 1967 desenhou um Estado repressor e autoritário, característico da ditadura instalada no país depois do golpe militar de 31 de março de 1964. O Brasil desta época apresentou a sua população um sistema público de saúde marcado pela restrição de acesso aos serviços de saúde (terapêutico, diagnóstico, ambulatorial, hospitalar). $O$ acesso a este sistema de saúde era dado somente aos brasileiros com emprego (relação trabalhista formal constituída), o que implicava na contribuição compulsória para o Instituto Nacional de Previdência Social (INPS) ${ }^{(1)}$. Assim, os trabalhadores devidamente identificados pelo sistema, cumprindo os prazos legais

(1) Para uma leitura mais detalhada da competência do INPS, ver art. $5^{9}$ da Lei $n .6 .439$, de $1^{9}$ de setembro de 1977. 
estipulados para carência, passavam a usufruir o seu direito à assistência médica hospitalar. Aos desempregados ou aqueles à margem do processo formal de geração de produção-emprego-renda restavam-Ihes o socorro pela solidariedade religiosa, congregadas nas Santas Casas de Misericórdia ou, via de regra, entregues a própria sorte.

Em 1977, o INAMPS ${ }^{(2)}$, braço do Sistema Nacional de Previdência Socia|(3) responsável pela assistência médica, foi instituído para dar conta deste sistema público de saúde de ação curativa, não contemplando em seu organograma as funções de auditoria. Na perspectiva de promoção da saúde e prevenção à doença, o que havia neste período eram postos de saúde espalhados pelos municípios brasileiros, pouco equipados e com resolutividade duvidosa. Programas de saúde (tuberculose, hanseníase, malária etc.), na assistência; campanhas de imunizações contra algumas doenças infecto-contagiosas, na prevenção, traduziam a tônica das ações de saúde realizadas.

Nas grandes cidades, o INAMPS constituía sua rede na materialidade presente dos Postos de Assistência Médica - PAM ${ }^{(4)}$, destinados à assistência médico-ambulatorial, exames complementares de diagnóstico e terapêutica e outras atividades-meio. Restou evidenciado o modelo de sistema de saúde vigente no país, com a era INAMPS. Restrição de acesso, coparticipação no custeio da assistência, pelo critério de nível de renda etc. $\mathrm{Na}$ eventualidade, o Estado em caráter compensatório, prestava assistência dirigida à população carente, através do seu braço para Assistência Social, a Legião Brasileira de Assistência - LBA ${ }^{(5)}$, que com o tempo acabou por se constituir em um dos grandes albergues de corrupção da velha república.

O serviço de auditoria deste sistema de saúde, de direito nunca existiu, mas sim a figuração de profissionais médicos que desempenhavam as funçōes de autorização de internação hospitalar e revisão de contas médicas, comumente confundida como sendo atividades de auditoria, por conta da incapacidade ou mesmo impossibilidade de compreensão da significaçăo das ações de auditoria para própria gestão do sistema e, da quase exclusividade desta modalidade de assistência, pela característica intrínseca do sistema vigente, hospitalocêntrico.

(2) INAMPS: Autarquia vinculada ao Ministério da Previdência e Assistência Social, sistema criado pela Lei n. 6.439, de $1^{9}$ de setembro de 1977, com a finalidade de integrar as funções de: concessão e manutenção de benefícios e prestação de serviços, custeio de atividades e programas, gestão administrativa, financeira e patrimonial.

(3) Para uma leitura mais detalhada, ver arts. $6^{\circ}, 7^{\circ}$ e $8^{\circ}$, todos da Lei n. 6.439 , de $1^{9}$ de setembro de 1977.

(4) PAM: prédios de grande área física construída, cujas dimensões destoavam em relação às demais disponibilizadas para este fim.

(5) À LBA compete prestar assistência social à populaçāo carente, mediante programas de desenvolvimento social $\mathrm{e}$ de atendimento às pessoas, independentemente da vinculaçāo destas à outra entidade do Sistema Nacional de Previdência e Assistência Social. 
Em um Estado de exceção, não é difícil deduzir que outras instâncias de controle, interno ou externo, capitulavam diante da autoridade do poder militar. Portanto, as funções de controle externo do Tribunal de Contas do Estado - TCE, no auxílio ao poder legislativo, na fiscalização dos gastos públicos do governador e dos prefeitos eram, neste período, apenas protocolares.

O novo desenho de Estado democrático conferido pela Constituição Federal de 1988, com funções de proteção social e garantias coletivas formalizadas num sistema de Seguridade Social, estabeleceu as regras básicas para criação do Sistema Único de Saúde - SUS. A saúde enquanto direito de cidadania e de dever do Estado(6), provido por um sistema público e único de saúde com princípios basilares de acesso, centrados na universalidade, integralidade das ações e eqüidade da atenção, operacionalizado por uma rede de açōes e serviços regionalizada e hierarquizada, sob gestão descentralizada, gratuito e com a participação da comunidade, materializou na Constituição Federal de 1988 os ideais do Movimento Sanitário(7). Antes da abordagem propriamente dita do SUS, deve ser ressaltado que este Estado, em contraponto ao anterior, já configura uma nova ordem social, política e econômica, bastando para tanto a análise das novas competências dos municípios ${ }^{(8)}$.

Os municípios agora passavam a prestar serviços de atendimento à saúde da população sendo criadas as Secretarias Municipais de Saúde e, como unidades orçamentárias, capacitaram-se à gestão das políticas públicas do setor saúde (planejamento e aplicação dos recursos públicos destinados para este fim, pelas três esferas de governo). Era o início do processo de descentralização, cabendo ao Secretário Municipal da Saúde colocar em prática a política de saúde traçada para o período de sua gestão, tomando as medidas administrativas necessárias para torná-las realidade.

É verdade que rapidamente a reforma do aparelho do Estado, iniciada no país na década de 90 , buscando aumentar as condiçōes de governança passou a transfigurar o Estado da Constituição de 1988. A reforma do apareIho do Estado teve no seu Plano Diretor, documento do núcleo estratégico do governo do Sociólogo Fernando Henrique Cardoso, o instrumento vetorial para redesenhar o papel do Estado no campo econômico, social, político e

(6) Para uma leitura mais detalhada, ver arts. 196, 197 e 198, todos da Constituição Federal do Brasil de 1988.

(7) Movimento de intelectuais, da academia e profissionais da saúde — na década de 80 no Brasil — cujo ideário buscava a construção de um Estado Social, compreendida a saúde enquanto direito de cidadania com a participação da população na construção e no usufruto das políticas públicas do setor saúde, sob efetivo controle social. O Relatório da $8^{\mathrm{a}}$ Conferência Nacional de Saúde, ocorrida em 1986, passou a constituir a proposta de democratização da saúde no país, fruto das lutas deste Movimento congregadas no Projeto de Reforma Sanitária, que introduziu na Constituição de 1988, os avanços sociais e as garantias individuais e coletivas.

(8) Para uma leitura mais detalhada, ver art. 30 da Constituição Federal do Brasil de 1988. 
gerencial (Modesto, 1977). Sem dúvida a trajetória de transformações deste Estado marcam o retrocesso ou o afastamento dos avanços dos direitos sociais, previamente conquistados e afirmados no texto constitucional. Como ensina Demo (Demo, 1977), direito não vem antes de cidadania. Ou ainda mais, como sentencia Barros: soluções baseadas na seletividade, focalização e privatização significarão a reprodução de desigualdades e o aprofundamento da segmentação social, no sentido de que se consagrarão critérios meritocráticos para o acesso às condições de exercício dos direitos sociais (Barros apud Misoczky, 2002, p. 104).

A promulgação da Constituição de 1988 determinou o início do processo de criação e implementação do novo sistema público de saúde do país, que acabou por materializar-se em um conjunto de leis, decretos, portarias e demaiš instrumentos normativos, visando garantir o cumprimento dos preceitos constitucionais.

A Lei n. 8.080, de 19 de setembro de 1990, também conhecida como Lei Orgânica da Saúde, dispõe sobre as condições para promoção, proteção e recuperação da saúde, a organização e o funcionamento dos serviços correspondentes. A Lei n. 8.142, de 28 de dezembro de 1990 decorreu da reapresentação dos artigos vetados na Lei n. 8.080/90, pelo Presidente Fernando Collor de Mello. A Lei n. 8.142 dispõe sobre a participação da comunidade na gestão do SUS, instituindo que o sistema público de saúde contará, sem prejuízo das funções do Poder Legislativo, de duas instâncias colegiadas: a Conferência de Saúde e o Conselho de Saúde.

O SUS deve observar os princípios e diretrizes constitucionalmente definidos que apontam o norte da formulação da Política Nacional de Saúde. O primeiro dos princípios do SUS assegura a todo e qualquer brasileiro o acesso universal às ações e aos serviços de saúde para sua promoção e recuperação. A universalidade como princípio, por si só, já determina uma verdadeira revolução na forma de se lidar com os direitos dos cidadãos brasileiros. Outro princípio do SUS é o da garantia da integralidade da assistência à saúde, o que significa dizer que há o compromisso público em prover às necessidades de saúde das pessoas e das coletividades de modo completo.

O princípio da eqüidade dá a garantia de que todos os cidadãos brasileiros, independentemente de sexo, raça, etnia, religião, idade ou situação de emprego, têm à mesma assistência para uma mesma necessidade. Significa ainda, que em função das diferenças sociais e das disparidades regionais, os recursos financiadores para saúde, deverão ser distribuídos numa lógica de favorecer aqueles que mais necessitam de atenção e cuidados. Estamos assim diante de uma questão de justiça social e uma forma de redistribuição de renda, num país marcado pela absoluta e crescente concentração de renda. 
Os princípios de universalidade de acesso e eqüidade da atenção levam a outro princípio do SUS, nos termos do art. 43 da Lei n. 8.080/90: a gratuidade das açōes e serviços de saúde oferecidos pelo SUS.

O princípio da descentralização refere-se ao processo de ampliação das responsabilidades nas três esferas de governo, pela formulação de políticas de saúde, seu planejamento, sua operacionalização e controle social. A descentralização e hierarquização levam à orientação estratégica da municipalização e da regionalização como formas de gestão capazes de acelerar e efetiva implantação do SUS.

A regulamentação destes princípios e, especialmente a operacionalização das estratégias para gestão, passou a delinear o sistema de saúde. Em 1991, o SUS começa a ser esculpido a golpes de portaria, sentencia Goulart (Goulart apud Misoczky, 2002, p. 81). Era o início das Normas Operacionais Básicas que passariam a definir os objetivos e as diretrizes estratégicas para a implantação do Sistema de Saúde, estabelecendo as normas e formas de operacionalização das relações entre os entes estaduais, municipais e o Distrito Federal.

A participação da comunidade nos serviços e nas ações de saúde foi assegurado na Constituição de 1988. O Conselho de Saúde é um órgão permanente de fiscalização do Sistema Único de Saúde, previsto na Constituição Federal e nas Leis ns. 8.080/90 e 8.142/90, e atua na formulação de estratégias e no controle da execução da política de saúde, inclusive nos aspectos econômicos e financeiros. O Conselho de Saúde é composto por representantes dos usuários, dos trabalhadores de saúde, do governo e dos prestadores de serviço, e sua existência no Município, no Estado e na União é exigência legal para que os recursos financeiros sejam repassados aos seus respectivos órgãos de saúde. A Resolução n. 33 do Conselho Nacional de Saúde (CNS) define a composição dos Conselhos de Saúde, com ênfase na garantia de ver nos mesmos, a participação comunitária representada. A composição deve ser paritária dos usuários, em relação aos outros segmentos sociais representados (50\% de usuários, $25 \%$ de trabalhadores de saúde, $25 \%$ de prestadores de serviços públicos ou privados).

A partir da criação do SUS, a política nacional de saúde é formulada pelo Ministério da Saúde com a participação do CNS. É papel dos ConseIhos de Saúde participarem na formulação das políticas de saúde, acompanhar a implantação das ações escolhidas, fiscalizar e controlar gastos, prazos, resultados parciais e a implantação definitiva dessas políticas. Os atos administrativos e burocráticos necessários à implantação das políticas de saúde municipais ou estaduais são obrigações das prefeituras ou governos estaduais, através de suas Secretarias da Saúde, e devem ser fiscalizadas pelos Conselhos de Saúde. Então, os Conselhos de Saúde são mecanismos de controle social das políticas públicas de saúde, com atuação específica no controle político-administrativo. Esta atuação articulada com outras ins- 
tâncias de controle, interno ou externo, como a Auditoria do SUS, o Tribunal de Contas do Estado e o Ministério Público, fortalece-a individualmente ao potencializar a eficácia de suas funções de controle como um todo.

O papel da Auditoria no Sistema Único de Saúde é balizado por todo um arcabouço jurídico e normativo dado especialmente pelas Leis Federais ns. 8.080 , de 19 de setembro de $1990^{(9)}, 8.689$ de 27 de julho de $1993^{(10)}$ e o Decreto Federal n. 1.651, de 28 de agosto de 1995, este último buscando a regulamentação do SNA ${ }^{(11)}$. No Rio Grande do Sul o Decreto Estadual n. 38.546, de 5 de julho de 1998, instituiu o Sistema Estadual de Auditoria (SEA) no âmbito do SUS ${ }^{(12)}$ e a Lei n. 11.867 , de 17.12 .02 criou os procedimentos administrativos do SEA e as medidas aplicáveis às irregularidades ocorridas no SUS no Estado e deu outras providências.. ${ }^{(13)}$

Sem prejuízo, sublinhe-se que as açōes da auditoria do SUS, que se caracterizam por funçōes típicas de Estado(14) debruçam-se, em caráter técnico, sobre as políticas públicas que - em movimento - visam promover, prevenir, assistir e recuperar a saúde da população, sobre os recursos públicos destinados ao financiamento destas políticas e, por fim, na constatação dos impactos gerados - melhoria dos indicadores de saúde - por estas políticas públicas que visem atingir transformaçōes qualitativas das condições de saúde.

A auditoria possui os instrumentos indispensáveis à fiscalização técnica do SUS, o que não acontece, até os dias de hoje com o Tribunais de Contas dos Estados e com os Conselhos de Saúde. Ademais, a auditoria tem um caráter propositivo no intuito de impulsionar os sistemas municipais de saúde a, efetivamente, cumprirem com as políticas públicas, que construídas junto aos seus respectivos Conselhos de Saúde venham a atender em consonância com os demais ditames legais do sistema e diretrizes outras dos gestores Estaduais e Federal.

O TCE ${ }^{(15)}$ e os Conselhos de Saúde ${ }^{(16)}$ desempenham papéis de controle e fiscalização, que não se caracterizam por ações excludentes entre si ou

(9) Para uma leitura mais detalhada, ver arts. 16 e 33 da Lei n. 8.080, de 19 de setembro de 1990.

(10) Para uma leitura mais detalhada, ver art. $6^{\circ}$ da Lei n. 8.689, de 27 de julho de 1993.

(11) Para uma leitura mais detalhada, ver arts. $4^{8} \theta 5^{\circ}$ do Decreto Federal n. 1.651 , de 28 de setembro de 1995.

(12) Para uma leitura mais detalhada, ver arts. $1^{2}, 3^{9} \theta 10$, todos do Decreto Estadual n. 38.546 , de 5 de julho de 1998.

(13) Para uma leitura mais detalhada, ver arts. $2^{2}, 13,23$ e 24, todos da Lei Estadual n. 11.867, de 17 de dezembro de 2002.

(14) Funções de competência exclusiva do Estado, não podendo ser delegado ao mercado a sua execução.

(15) Orgão de controle externo, com normas previstas no que couber à organização, composição e fiscalização dos Tribunais de Contas dos Estados, no molde do estabelecido ao TCU, arts. 70 a 75 da $\mathrm{CF} / 88$.

(16) Órgão colegiado, em caráter permanente e deliberativo, com atuação na formulação de estratégias e no controle da execução da política pública de saúde na instância correspondente, $\S 2^{\ominus}$ do art. $1^{\circledR}$ da Lei n. 8.142, de 1990. 
em relação às ações da auditoria do SUS. Pelo contrário, constituem-se em forças complementares e potencializadas quando em ação sincrônica no interesse público. O TCE realiza a apreciação, dentro das suas atribuiçōes, da regularidade na utilização do conjunto de recursos públicos movimentados pelo estado e pelos municípios. Aos Conselhos de Saúde Estadual e Municipais, competem respectivamente, o controle e a fiscalização da execução das políticas públicas e mais, a construção destas políticas de saúde, postas em prática, pelo Gestor Estadual e pelos Gestores Municipais.

A criação do primeiro Tribunal de Contas no país, o Tribunal de Contas da União data de 1890, tornando-se a partir desta data imprescindível sua existência no controle externo da administração pública. O TCE do Rio Grande do Sul, previsto na Constituição Estadual de 1989, encontra-se disciplinado neste diploma legal, especialmente no que concerne a suas funçōes de fiscalização contábil, financeira e orçamentária ${ }^{(17)}$ e as demais competências deste órgão são dadas pela sua Lei Orgânica, Lei n. $11.424 / 00^{(18)}$ e pelo seu Regimento Interno(19) contido na pela Resolução n. 544/00 deste Tribunal.

As funções dadas pelas competências constitucionais, pela sua Lei Orgânica e pelo seu Regimento Interno, conferem ao TCE o poder de fiscalização sobre a gestão e o dever de zelar pelo patrimônio público, no estado e nos municípios. Ressaltem-se as diferenças das ações do Tribunal de Contas do Estado, e os Conselhos de Saúde: enquanto o primeiro presta assessoramento ao legislativo estadual e municipal, promovendo a apreciação da regularidade das contas públicas estadual e municipais, o segundo possui, além do papel fiscalizador, a prerrogativa de construção das políticas públicas em seu âmbito para o setor saúde.

Fica a questão: qual seria o papel da auditoria no SUS e as interfaces com o TCE e os Conselhos de Saúde?

Poucos autores abordaram este assunto, com enfoques distintos, seja na esfera das causas e circunstâncias da mortalidade materna (Supratikto et al., 2002), a confiabilidade na mesma na avaliação de qualidade da atenção médica (Camacho e Rubin, 1996) ou ainda na esfera da avaliação de procedimentos inseridos no programa de atenção integral à saúde da mulher (Costa e Roman, 1998). Com foco funcionalista têm-se estudos da estrutura e do processo na atenção pré-natal (Santos e Costa, 2001), a inspeção na mesma direção do trabalho e controle social (Miranda, 2004) e as contribuições do uso da metodologia quantitativa na auditoria de serviços de atenção primária à saúde (Bilbao Acedos et al., 2002).

(17) Para uma leitura mais detalhada, ver art. 70 da Constituição Estadual do Estado do Rio Grande do Sul de 1989.

(18) Para uma leitura mais detalhada, ver art. 33 da Lei n. 11.424/2000.

(19) Para uma leitura mais detalhada, ver art. $7^{\circ}$ do Regimento Interno do TCE-RS. 
Não foram encontrados trabalhos que investigassem o papel da auditoria no sistema público de saúde, de maneira especial, com relação aos sistemas municipais de saúde, dando assim, uma dimensão macro do processo com foco na gestão, como um todo orgânico-funcional do sistema de saúde.

Neste contexto emerge o objetivo deste artigo: identificar o papel da auditoria do Sistema Único de Saúde (SUS) empregando como estudo de caso auditorias de gestão realizadas no Estado do Rio Grande do Sul (RS) em 2003.

\section{MÉTODOS}

Este trabalho teve por base cinco auditorias de gestão, realizadas pelo gestor estadual no ano de 2003, em sistemas municipais de saúde do Estado do Rio Grande do Sul (RS). Das cinco auditorias, duas foram realizadas nos municípios de Santa Rosa e Panambi obedecendo ao critério de cumprimento do cronograma de auditorias (regulares) de gestão da Coordenação de Auditoria Médica da SES/RS. Estes dois municípios se encontravam habilitados à gestão plena do sistema municipal de acordo com a Norma Operacional Básica n. 01/96, ainda em vigência no ano de 2003. As outras três auditorias foram realizadas nos municípios de Ciríaco, Lagoa Vermelha e Viamão, atendendo a demandas externas ao gestor estadual: do Conselho Estadual de Saúde, do Prefeito Municipal e do Ministério Público Estadual, respectivamente. Estes três municípios se encontravam habilitados à gestão plena da atenção básica do sistema municipal de acordo com a Norma Operacional Básica n. 01/96, ainda em vigência no ano de 2003. A partir da edição da Norma Operacional da Assistência, NOAS/2002, foram acrescidas outras responsabilidades aos municípios sendo os mesmos habilitados à gestão plena da atenção básica ampliada - PABA.

Para o estudo de caso proposto foi utilizado como instrumento de pesquisa um formulário, com questões fechadas que abordavam requisitos técnicos à habilitação da gestão do SUS municipal (se estava instituído o componente municipal do Sistema Nacional de Auditoria; se as funções de auditoria sobre as ações e serviços ofertados se constituiriam em ferramenta de gestão do sistema municipal de saúde, especificando se as funções dos componentes estadual e municipal de auditoria contribuiriam para a consolidação do Sistema Único de Saúde, entre outros), visando também à identificação da contribuição direta das ações de auditoria nos princípios doutrinários do SUS.

O instrumento de pesquisa foi encaminhado aos Prefeitos Municipais, por três vezes seguidas, na tentativa de coleta de dados, todas sem êxito. As informações sobre os sistemas municipais de saúde foram obtidas nos relatórios 
de auditorias de gestão realizadas nestes municípios no ano de 2003 , pelo Sistema Estadual de Auditoria.

\section{RESULTADOS E DISCUSSÃO}

Os cinco gestores municipais não responderam ao instrumento de pesquisa, com prejuizo no tocante às duas questões que evocavam a emissão de um juízo de valor pelos gestores participantes. As demais questōes, de cunho técnico, foram obtidas junto ao relatório do SEA.

Dos cinco municípios auditados pelo gestor estadual, dois encontramse habilitados à gestão plena do sistema municipal de saúde, pela Norma Operacional Básica n. 01/96- NOB n. 01/96, o que deveria significar, terem cumprido todos os requisitos legais exigidos para esta condição de habilitação. A NOB n. 01/96 prevê para esta habilitação, a necessidade destes municípios terem instituído formalmente os componentes municipais do SNA e possuírem médicos auditores em seus quadros funcionais. As auditorias realizadas comprovaram que somente um dos dois municípios cumprira as exigências legais para sua condição de habilitação a gestão do SUS municipal.

Quanto aos outros três municípios, todos se encontravam habilitados à gestão plena da atenção básica de acordo com a NOB n. 01/96, o que determina a necessidade em seus quadros funcionais da presença de médico auditor, em efetivo exercício de suas funções técnicas. As auditorias de gestão realizadas demonstraram que nenhum dos três municípios atendeu a esta exigência legal, requisito condicionante à obtenção desta condição de gestão do SUS municipal.

Desta forma, em que pesem conhecimentos e experiências em outras áreas da administração pública que possam possuir estes agentes públicos, não executando as atividades de auditoria em seus sistemas municipais de saúde, pouco teriam estes gestores para contribuírem com as suas experiências nesta matéria específica.

Definir o papel da Auditoria do Sistema Único de Saúde significa fazer com que gestores, usuários e prestadores de serviços entendam que suas ações consubstanciam-se em controle interno técnico do Sistema SUS, para utilização pelos gestores, Conselhos de Saúde, prestadores de serviços e os cidadãos, usuários ou não, como efetivas ferramentas indispensáveis à tomada de decisões, por cada uma das representaçōes nominadas acima, na garantia do interesse público e no fiel cumprimento dos preceitos constitucionais e normativos do SUS.

Não há incompatibilidade nas ações da Auditoria, do TCE e dos ConseIhos de Saúde, tampouco razōes para excluírem-se. Mas, sim naturezas de origem, constituição e "olhares" distintos, cada qual com as suas identi- 
dades, peculiaridades e modus operandi próprios, desejavelmente autônomos e, portanto, com histórias no tempo que, respeitadas, as mantêm. Grife-se que a Auditoria e o TCE não participam do planejamento e da construção das políticas públicas postas em ação pelos gestores, a exemplo dos Conselhos de Saúde.

As ações da auditoria do SUS são capazes de tecnicamente identificarem e apontarem irregularidades e inconformidades na gestão frente às normas do sistema e demais bases legais do direito público. Também por dever de ofício, são apresentadas sugestões capazes de nortear alternativas corretivas com cunho saneador aos apontamentos feitos. Estas ações buscam atender a efetividade das políticas públicas praticadas, qualificando a gestão, possibilitando as condições técnicas para que estas biopolíticas cumpram as suas missões e, por extensão, que os recursos públicos destinados ao financiamento destas políticas sejam cada vez mais otimizados. Desta maneira evitar-se-á a duplicidade de ações e o desperdício do dinheiro público obedecendo ao princípio da economicidade e pautando, permanentemente, a conduta do agente público responsável pela gestão do sistema de saúde (o gestor da saúde), na probidade, na moralidade e na ética no trato da coisa pública.

Nesta perspectiva a auditoria contribui para que o Estado possa cumprir com o seu desafio constitucional de ser a saúde um direito do cidadão e - SUS o sistema público de saúde no Brasil. Através dos resultados das auditorias os gestores terão informaçōes privilegiadas e imprescindíveis ao planejamento e tomada de decisões para melhor investir os recursos públicos destinados ao financiamento do SUS, redirecionando-os, sempre que necessário, para açōes e programas que respondam às maiores necessidades da população e, na medida em que os financiamentos para saúde são deslocados para promoção e prevenção à saúde, afastando-os da assistência à doença, melhor estarão configurados os indicadores de saúde da população.

\section{CONCLUSÓES}

É sabido da necessidade de correçōes e reconfiguraçōes no SUS, pelo seu momento de consolidação. Compreendido como um processo necessita, permanentemente, de feedback para redirecionar as suas ações visando o cumprimento dos seus eixos basilares. Nesta perspectiva e com grande pertinência nas atividades de auditoria do SUS, o Sistema Nacional de Auditoria e os seus respectivos Componentes Estaduais e Municipais ainda hoje - aguardam regulamentação jurídica normativa, organização funcional fundada em um plano de carreira, cargos e salários e infra-estrutura logística capazes de conferir-lhes a efetiva identidade funcional de Auditor 
do Sistema Único de Saúde. Esta identidade então, permitirá a equivalência de competências, prerrogativas e reconhecimento intra/intergovernamental e, principalmente, junto à sociedade, a exemplo de outras instâncias que integram a máquina do Estado.

\section{REFERENCIAS}

BILBAO ACEDOS, Izaskun; MARCH CERDA, Joan Carles; PRIETO RODRIGUES, María Angeles. Ten contributions of the use of qualitative methodology in a Primary Care in-house audit. Rev. Esp. Salud Publica, v. 76, n. 5, p. 483-492, out. 2002.

BRASIL. Constituição da República Federativa do Brasil. 1967. Disponível em: <http://www.senado.gov.br>. Acesso em: 3.maio.2004.

. Constituição da República Federativa do Brasil. 1988. Disponível em: <http://www.senado.gov.br>. Acesso em: 3.maio.2004.

. Decreto n. 1.661, de 28 de setembro de 1995.

. Lei n. 6.439, de $1^{\circ}$ de setembro de 1977.

. Lei n. 8.080, de 19 de setembro de 1990.

. Lei n. 8.142, de 28 de dezembro de 1990.

. Lei n. 8.689, de 27 de julho de 1993.

. Ministério da Saúde. Conselho Nacional de Saúde. Resolução n. 33, de 23 de dezembro de 1990.

. Ministério da Saúde. Gestão Municipal de Saúde: textos básicos. Rio de Janeiro: Ministério da Saúde, 2001.

. Ministério da Saúde. Portaria n. 2.203, de 5 de setembro de 1996.

- Ministério da Saúde. Portaria n. 1.069, de 19 de agosto de 1999.

CAMACHO, Luiz Antonio Bastos; RUBIN, Haya Rahel. Confiabilidade da auditoria médica na avaliação de qualidade da atenção médica. Caderno de Saúde Pública, v. 12, supl. 2, p. 85-93, 1996.

COSTA, Juvenal Soares Dias da; MADEIRA, Ângela C. C.; LUZ, Rafael M. et al. Auditoria médica: programa de pré-natal em posto de saúde na região Sul do Brasil. Rev. Saúde Publica, v. 34, n. 4, p. 329-336, ago.2000.

COSTA, Juvenal Soares Dias da; ROMAN, Vânia Rosa; LUZ, Rafael Moura da et al. Auditoria médica: avaliação de alguns procedimentos inseridos no programa de atenção integral à saúde da mulher no posto de saúde da Vila Municipal, Pelotas, Rio Grande do Sul, Brasil. Caderno de Saúde Pública, v. 14, n. 1, p. 43-49, jan./mar. 1998. 
DEMO, Pedro. Menoridade dos mínimos sociais: encruzilhada da assistência social do mundo de hoje. Serviço Social e Sociedade, ano 18, n. 55, p. 3973, 1977.

MIRANDA, Carlos Roberto; DIAS, Carlos Roberto. PPRA/PCMSO: auditoria, inspeção do trabalho e controle social. Caderno de Saúde Pública, v. 20, n. 1, p. 224-232, jan./fev.2004.

MISOCZKY, Maria Ceci. O campo da atenção à saúde após a Constituição de 1988. uma narrativa de sua produção social. 2002. 186 p. Tese (Doutorado) - UFRGS, Porto Alegre, 2002.

MODESTO, Paulo. Reforma administrativa e marco legal das organizações Sociais no Brasil - as dúvidas dos juristas sobre o modelo das organizações sociais. Revista do Serviço Público, Brasília, v. 48, n. 2, p. 27-58, maio/ ago.1977.

RIO GRANDE DO SUL (Estado). Constituição Estadual, 1988.

- Decreto n. 38.546/98, de 5 de junho de 1998. . Lei n. 11.424, de 6 de janeiro de 2000 . . Lei n. 11.867, de 17 de dezembro de 2002.

2000. . Tribunal de Contas do Estado. Resolução n. 544, de 21 de julho de

RODRIGUES NETO, Eleutério. A reforma sanitária e o Sistema Único de Saúde: suas origens, suas propostas, sua implantação e suas perspectivas. Brasília: Ministério da Saúde, 1998.

ROSA, Roger dos Santos; BORDIN, Ronaldo. Aspectos da reforma do Estado e de Setores da seguridade social. Porto Alegre, 2003.

SILVEIRA, Denise Silva da; SANTOS, Iná Silva dos; COSTA, Juvenal Soares Dias da. Atenção pré-natal na rede básica: uma avaliação da estrutura e do processo. Caderno de Saúde Pública, v. 17, n. 1, p. 131-139, jan./fev.2001.

SUPRATIKTO, Gunawan; WIRTH, Meg E.; ACHADI, Endang et al. A districtbased audit of the causes and circumstances of maternal deaths in South Kalimantan, Indonesia. Bull World Health Organ, v. 80, n. 3, p. 228-235, 2002. 